\title{
The role of the store in managing postpurchase complaints for omnichannel shoppers
}

\author{
Maria-Jose Miquel-Romero*, Marta Frasquet, Alejandro Molla-Descals \\ Marketing Department, University of Valencia, Spain
}

A R T I C L E I N F O

\section{Keywords:}

Complaint channel

Physical stores

Dissatisfaction

Redress seeking

Assertiveness

fsQCA

\begin{abstract}
A B S T R A C T
This paper focuses on postpurchase complaint behavior to understand under which conditions omnichannel shoppers choose to complain at the physical store instead of doing it through online channels. Using fuzzy-set Qualitative Comparative Analysis (fsQCA), we find that four different combinations of situational, channelrelated, and individual variables lead to complaining at the store. The motivation of seeking redress together with assertiveness and high dissatisfaction, play an essential role in the choice of complaint channel. The channel of purchase is not determinant for the choice of the store to complain. These findings have implications in terms of redefining the role of the store in the current omnichannel era.
\end{abstract}

\section{Introduction}

Retail businesses have evolved from single to multi- to omnichannel models by integrating new channels within the existing offline and online mix, and focusing on the interplay between channels (Verhoef, Kannan, \& Inman, 2015; Zhang, Ren, Wang, \& He, 2018). The mobile channel (i.e., shopping through a smartphone or tablet) and social media are central elements of the omnichannel concept (Verhoef et al., 2015); omnichannel encompasses not only purchase channels, but also communication channels, blurring the notions of push and pull channels (Ailawadi \& Farris, 2017), as the boundaries that once separated the channels disappear (Juaneda-Ayensa, Mosquera, \& Murillo, 2016).

The physical store plays a new role in the omnichannel context, where consumers interact with retailers through multiple channels and touchpoints during the shopping process (Lemon \& Verhoef, 2016). From being a sales channel in parallel to the online channel, physical stores are evolving and integrating with online channels. Thus, the store acts as a showroom that the customer can visit before purchasing online, as a collection point for online purchases, or as a post-purchase customer service centre (Bell, Gallino, \& Moreno, 2018). In this context, the store could become influential in the postpurchase stage, not only by managing product returns but also by managing customer complaints about issues in any channel. This paper addresses the relevance of physical stores in customer complaint management in the omnichannel era.

The availability of multiple channels to interact with firms is transforming consumer behaviour throughout the entire shopping process (van Bruggen, Antia, Jap, Reinartz, \& Pallas, 2010). Although their use is polarised in specific customer segments, mobile and social media channels have become increasingly popular in recent years (Sands, Ferraro, Campbell, \& Pallant, 2016). The challenge for researchers is to understand how consumers integrate offline and online channels in the different stages of their shopping processes (Lemon \& Verhoef, 2016; Verhoef et al., 2015). The channels literature has investigated the choice of channels across the shopping stages (e.g., Konuş, Verhoef, \& Neslin, 2008); however, few studies have analysed the shopping process including the postpurchase stage, and they have not explicitly contemplated complaining behaviours (De Keyser, Schepers, \& Konuş, 2015; Frasquet, Mollá, \& Ruiz, 2015; Gensler, Verhoef, \& Böhm, 2012).

Complaining is a behaviour emerging from dissatisfaction with the product or service, typically occurring after purchase. The digital revolution has provided consumers with new online channels to complain (Berry, Tanford, Montgomery, \& Green, 2018). Following this trend, firms are implementing multichannel complaint management systems to be able to respond to customers through any channel (De Keyser et al., 2015). Among online channels, social media is becoming an increasingly popular way to interact with firms (Dalla Pozza, HeitzSpahn, \& Texier, 2017) and is having significant implications when customers use it to spread negative opinions (De Keyser et al., 2015; Istanbulluoglu, Leek, \& Szmigin, 2017). The literature on complaint channel choice is very scarce and has not considered social media channels yet. Mattila and Wirtz (2004) analysed the choice of online versus offline channels to voice complaints to firms. Lee and Cude

\footnotetext{
* Corresponding author at: Faculty of Economics, Avda. Los Naranjos, s/n, Valencia 46022, Spain.

E-mail address: maria.j.miquel@uv.es (M.-J. Miquel-Romero).
} 
(2012) studied how the likelihood of using different complaint channels differed between online and offline buyers, but they did not focus on direct complaints to firms. Complaining to firms have specific motivations in contrast to broader complaint behaviours such as telling the story to friends, and the implications for the firm differ as well (Istanbulluoglu et al., 2017).

The main aim of this paper is to gain a deeper understanding of postpurchase complaint behaviour in the omnichannel context. More specifically, we investigate the choice of the physical store to voice complaints to the firm when the customer has different channels available. We analyse this choice as a function of situational variables (i.e., purchase channel, dissatisfaction), individual characteristics (i.e., redress seeking, assertiveness, social media habit strength), and channel-related variables (i.e., convenience, perceived benefits of store employees). In this way, our study contributes, firstly, to the literature on complaint channels as it analyses complaining to firms as a function of variables specific to the omnichannel context, and secondly, to the channels literature by analysing interactions between channels at the purchase and postpurchase complaint stages.

This paper builds on complexity theory and employs fuzzy-set Qualitative Comparative Analysis (fsQCA) (Ragin, 2008; Woodside, 2013). This methodology has been increasingly used in marketing because, together with complexity theory, it offers a richer perspective on the data (Leischnig \& Kasper-Brauer, 2015; Mozas-Moral, BernalJurado, Medina-Viruel, \& Fernández-Uclés, 2016; Pappas, Kourouthanassis, Giannakos, \& Chrissikopoulos, 2016). In this way, we attempt to uncover which patterns or combinations of the situational, channel-related, and individual variables cited above lead to the choice of the physical store as the complaint channel.

The structure of this paper is as follows. After this introduction, Section 2 provides the conceptual framework of our study; Sections 3 and 4 describe the methodology and results respectively; Section 5 presents the discussion, together with the study's managerial implications and limitations. Finally, Section 6 completes the paper with a conclusion.

\section{Conceptual framework}

Customer complaint behaviour (CCB) is defined as the full range of consumer responses to dissatisfaction regarding a particular consumption experience, which encompasses behavioural and non-behavioural complaining actions that can be performed simultaneously or successively (Istanbulluoglu et al., 2017). Within behavioural actions, voice is the decision to communicate the complaint to others, being peers or the firm (Hirschman, 1970). This study focuses on voicing complaints to the firm. Complaint actions are sorted into two categories: private and public complaints (Singh, 1988). Private complaining means that the customer voices his or her complaint only to the company, whereas public complaining goes beyond the company domain as the consumer tries to warn others or merely seeks revenge (Svari \& Erling Olsen, 2012). Nowadays, to voice their complaints, individuals have many available channels, classified as remote (e.g., email) or interactive (face-to-face) (Mattila \& Wirtz, 2004). Social media is classified as a semi-interactive channel as it is in between remote and interactive channels (Clark, 2013).

As implicit in the definition of CCB, much of the literature has considered complaining as a function of dissatisfaction (e.g., Bearden \& Teel, 1983); however, other factors and emotions motivate the customer to complain (Day, 1984; Tronvoll, 2011). Investigating complaint channel choice in the context of omnichannel retailing calls for the inclusion of new variables in the research framework. Based on the stimulus-organism-response (S-O-R) model (Mehrabian \& Russell, 1974), we understand the choice of the complaint channel as a function of external stimuli (i.e., situational and channel-related variables) and characteristics of the consumer (i.e. individual characteristics). Therefore, we suggest that the choice of the store for complaining can be related to the following variables: (1) purchase channel, (2) level of dissatisfaction, (3) redress seeking, (4) assertiveness, (5) social media habit strength, (6) perceived channel convenience, and (7) perceived benefits of store employees.

The channel used to complain may be dependent on the purchase channel. The channels literature has discussed the interactions between channels during the shopping process. Channel lock-in refers to the extent to which a channel keeps shoppers from one stage of shopping to the next; this is the opposite of the synergy effect, which refers to either the combination of channels or cross-shopping behaviours (Gensler et al., 2012; Verhoef, Neslin, \& Vroomen, 2007). Initially, studies investigated the interactions between the information and purchase stages, identifying a strong lock-in effect of the offline channel and the synergies explaining webrooming and showrooming behaviours. As argued by Lemon and Verhoef (2016:83), "the effect of an individual touchpoint may depend on when it occurs in the overall customer journey". The findings related to the dependencies between the purchase and postpurchase stages are not conclusive. Gensler et al. (2012) found that channel choice for postpurchase is affected by the purchase channel; however, De Keyser et al. (2015) and Frasquet et al. (2015) suggest that most online buyers visit the store for postpurchase service. While these studies do not include social media as a channel, Sands et al. (2016) uncovered an increasing use of social media across all shopping stages. Moreover, the previous studies do not explicitly consider the postpurchase complaint action, and as a result, we need to complement them with CCB literature. Lee and Cude (2012) ascertained that online buyers were more likely to use online channels to complain and offline buyers more likely to use offline complaint channels. Frasquet, Miquel, and Mollá (2017) found that offline buyers tend to complain at the store, but the relationship between online purchases and offline complaints was not significant. All in all, we could expect a lock-in effect between the purchase and the complaint channel when the purchase is made offline, whereas in the case of online purchase the lock-in effect is not apparent, and the synergy effect also seems possible.

The CCB literature argues that a higher degree of dissatisfaction leads to a higher intention to complain (Thøgersen, Juhl, \& Poulsen, 2009). This link has been identified in the offline shopping context as well as in online retailing (Wu, 2013). However, research investigating the effect of dissatisfaction not on the intention to complain but on the choice of complaint channel is scarce. Although Lee and Cude (2012) analysed the interaction effect of dissatisfaction in the relationship of purchase and complaint channels, finding that very dissatisfied online buyers tend to use online channels to complain, they could not confirm that the level of dissatisfaction affected the choice of complaint channel used by offline buyers. We believe that when the level of dissatisfaction is high, both online and offline shoppers would prefer to complain at the store as this channel could be more effective in terms of clarifying the issue (Mattila \& Wirtz, 2004).

The CCB literature has identified redress seeking as one of the main motivations of the consumer for complaining to firms (Day \& Landon, 1977; Istanbulluoglu et al., 2017). Redress seeking as an individual motivation refers to the belief by the consumer that the company should "make things right" in the case of service failure (Day, 1984: 498). The redress seeker demands that the firm takes responsibility for the remedy and rectification of a problem, offering a replacement, refund, repair, or any other type of compensation (Mattila \& Wirtz, 2004). The results of Mattila and Wirtz (2004) reveal that the redress seeking motivation is related to the choice of interactive channels to complain (in their study, face-to-face and phone) versus remote channel (letter or email). Complaining face-to-face at the store allows the dissatisfied shopper to clarify matters, explain in detail, and show feelings that could make the complaint more effective.

Despite being dissatisfied and willing to get compensation, some consumers choose not to complain for a variety of reasons (Istanbulluoglu et al., 2017). Other individual characteristics play a role 
in explaining consumer reactions to a dissatisfactory event (Lau \& $\mathrm{Ng}$, 2009). Voicing a complaint bears psychological costs for consumers, mainly if they are high in shame proneness (Mattila \& Wirtz, 2004). In contrast, assertive consumers would not experience such high costs. Assertiveness is a communication approach characterised by firmly expressing one's opinion in front of others; it is related to a tendency to approach arguments instead of avoiding them, and to maintain one's identity (Lapinski \& Orbe, 2007); therefore, it is expected to play a role in the complaint task. Moreover, as complaining at the store implies face-to-face confrontation (Mattila \& Wirtz, 2004), it is expected that consumers that are high in assertiveness would use this channel.

Other individual characteristics may affect the choice of complaint channel. Today, consumers increasingly use social media to interact with firms (Dalla Pozza et al., 2017), but not all of them are equally familiar with this form of media. The choice of the physical store to complain would be more relevant when the consumer is not in the habit of using social media to interact with others. Habit strength represents a recurring behaviour pattern established by past thinking about the benefits of using the channel that is expected to influence ongoing behaviour (Larose \& Eastin, 2004). Social media habit strength is a variable that should be related to social media use more directly than social media-self efficacy or prior experience with the media (Larose, Lin, \& Eastin, 2003). Thus, we believe that when social media habit is not very strong, consumers will tend to complain in store.

Channel convenience refers to the practicality of the channel or the perceived ease and speed with which a consumer can gather information, purchase a product, or conduct postpurchase actions (Cervellon, Sylvie, \& Ngobo, 2015; Gensler et al., 2012). Perceived convenience has a positive effect on consumers' channel choices (Frambach, Roest, \& Krishnan, 2007; Gensler et al., 2012) as they will generally use channels perceived as more convenient; Schröder and Zaharia (2008) found that consumers choose online channels because of increased convenience. Although there is no empirical support regarding the role of convenience in using specific channels to complain, Gensler et al. (2012) demonstrated that convenience was the strongest predictor of channel choice in the postpurchase stage. Complaining is not an easy regular task, and consumers will tend to use the channel they perceive as more convenient to access and to voice the complaint to the firm. For both online and offline buyers that are not very familiar with social media or are high in assertiveness, complaining face-to-face at the store should be more convenient (Snellman \& Vihtkari, 2003).

One of the most significant advantages of physical stores over online channels is the social interaction with store employees, which adds to the shopping experience (Bell et al., 2018; Mattila \& Wirtz, 2008). Customers derive value from the interaction with store employees (Reynolds \& Beatty, 1999b), and this has positive impacts on store performance and attitudes towards the retailer (Reynolds \& Arnold, 2000). Salespersons can help customers to find the desired product and to make the purchase choice, providing valuable advice during the shopping process. Shoppers driven by utilitarian shopping motivations value the benefits of employees as they provide time-savings and relief from shopping, whereas those who enjoy shopping should value the advice and the social interaction with employees (Reynolds \& Beatty, 1999a). O'Cass and Grace (2008) argue that the behaviour of store employees can affect the customer's response to the service encounter. Thus, the perceived benefits of store employees may play a role in the decision to visit or not visit the store for postpurchase complaining.

Considering the scarce literature and mixed results regarding CCB in a multi/omnichannel retailing context, the present study adopts complexity theory via fsQCA. This method allows to identify the causal patterns or configurations leading to the choice of the physical store for complaining. The principle of equifinality considered by complexity theory is assumed; this implies that different sets of causal conditions can equally explain the outcome of interest (in our analysis, the six previously explained variables linked to offline complaint channel choice), which combine in sufficient configurations for the outcome

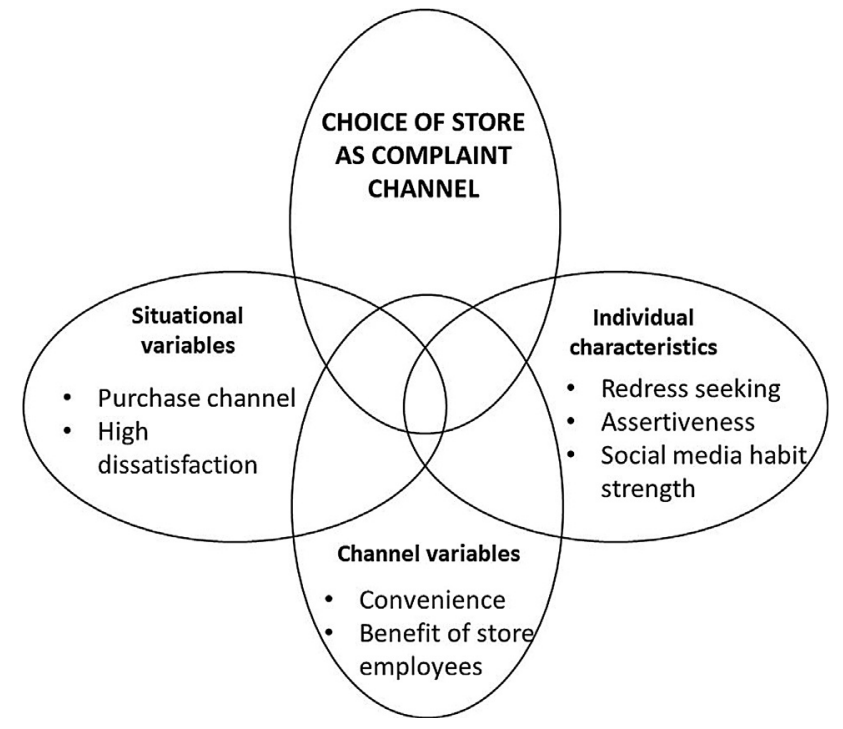

Fig. 1. Conceptual model.

(Woodside, 2016). Complexity theory also considers the principle of causal asymmetry, which argues that for an outcome to occur a causal condition can be present or absent depending on how that causal condition combines with others (Woodside, 2016). Based on those two principles, equifinality and asymmetry, we adapt a proposition generally applied in FsQCA studies to our context:

There is more than one causal configuration or combination of situational variables, individual characteristics, and/or channel-related variables, leading to the choice of the physical store for complaining.

Fig. 1 is a Venn diagram summarising the conceptual model derived from the general proposition.

Based on the literature review, we can make the general fsQCA proposition more specific. We suggest the relationship of each variable of our study to the outcome (i.e., store complaint) (proposition 1), and some of the expected combinations of those variables that can produce the outcome (proposition 2). Accordingly:

Proposition 1. Choosing the store to complain relates to (a) purchasing offline, (b) high dissatisfaction, (c) high redress seeking motivation, (d) high individual's assertiveness, (e) low social media habit strength, (f) high perception of channel convenience, and (g) high perception of store employees' benefits.

Proposition 2. Choosing the store to complain relates to (a) offline purchase and motivation of redress seeking, (b) low social media habit strength and high perception of channel convenience, (c) low social media habit strength and high individual's assertiveness, (d) offline purchase and high perception of store employees' benefits.

\section{Methodology}

Data was collected via a survey to an online Spanish panel. The population consisted of omnichannel shoppers in the apparel product category who were behavioural complainers. Several filters allowed to select the interviewees: use of social media, use of different channels during a shopping process, and having complained at least once in the last year. The sampling procedure established age and gender quotas to represent the population under study, whereby participants were $60 \%$ female, and the average age was 40 years.

The questionnaire had two parts. The first consisted of questions about the individual's traits and habits, and the second consisted of an experiment that contained one of two possible scenarios (see Appendix I). Both scenarios described the same issue with an unidentified multichannel retailer likely to provoke high dissatisfaction in the shopper so that it would make sense to voice a complaint; in scenario A, the 
individual purchased in a physical store; in scenario B, the channel of purchase was the online channel. After reading the situation, the individuals had to provide information about their level of dissatisfaction with the issue. They then had to choose the specific channel they would use to complain (physical store, email, or social media) assuming all of the options were equally available. Apart from the choice of complaint channel, all measures were 7-point Likert scales taken from previous literature. Of all the participants sampled (577 individuals), 367 chose complaining in the physical store or through social networks. Among them, $82.8 \%$ chose complaining at the physical store (304 individuals) and $17.2 \%$ through social media (63 individuals). More precisely, from those facing scenario A, $84.4 \%$ would complain at the physical store with a similar percentage for those facing scenario B (80.8\%).

Before testing the propositions, we checked the psychometric properties of the scales via a confirmatory factor analysis with EQS 6.1 using the robust estimation method. All values of the relevant indicators confirm the reliability and validity of the measures (see Appendix II).

FsQCA was utilised to explore the research propositions. This technique analyses how causal conditions (in our analysis these consist of: channel of purchase, high dissatisfaction, redress seeking, social media habit strength, assertiveness, perceived channel convenience, and perceived benefits of store employees) lead to a particular outcome (choosing the physical store for complaining) (see Ragin, 2008 for details). Although in both analysed scenarios (online and offline purchase) most dissatisfied individuals choose the physical store to complain, the fsQCA helps in modelling multiple realities (different combinations of causal conditions) leading to the same choice of complaint channel, i.e., the physical store.

FsQCA works with variables measured on one single item. Consequently, we calculated the average of each multi-item scale. The following step was to calibrate the data. Calibration of the measures is a crucial stage of fsQCA as this procedure allows us to translate construct measures into fuzzy set membership scores. The fsQCA program requires at least three substantively meaningful thresholds in order to transform variables into calibrated sets: full membership (1), full nonmembership (0), and cross-over point (i.e., the point of maximum ambiguity - 0.5) (Ragin, 2008). We employed a direct method for calibration (see Ragin, 2008). Specifying the original values for the three breakpoints permits the software to calibrate all remaining scores. In a similar manner to previous research on a similar topic (e.g., Pappas et al., 2016), the three qualitative anchors for the calibration considered the survey scale: the full membership threshold was fixed at a rating of 6 , the full non-membership threshold was fixed at 2 , and the crossover point was fixed at 4. Next, fsQCA analysed how membership of cases in causal conditions linked to membership in the outcome (Ragin, 2008).

\section{Results}

The results of fsQCA allow us to identify the configurations of causal conditions leading to choose the physical store for complaining. As Ragin $(2000$; 2008) posits, a causal condition (or configuration) is sufficient for the outcome if by itself it produces the outcome. Table 1 shows the intermediate solution results, which reach the minimum criteria for overall consistency and coverage considered adequate for sufficiency (0.75 and 0.60, respectively) (Ragin, 2000). Consistency scores closer to 1 denote a more perfect subset relationship. The overall solution coverage - comparable to the R-square value (Woodside, 2013) - indicates the extent to which choosing the physical store to complain can be related to a set of configurations. Accordingly, the four solutions altogether explain $75 \%$ of the cases reporting the selection of the physical store to complain. The inspection of coverage values of each specific solution enables us to assess the relative importance of causal condition configurations for the outcome. Raw coverage measures "the relative importance of several combinations of causally relevant
Table 1

Sufficient configurations that lead to the physical store being chosen to complain.

\begin{tabular}{|c|c|c|c|c|}
\hline \multirow[b]{2}{*}{ Configuration } & \multicolumn{4}{|c|}{ Solutions (causal configurations) $)^{a}$} \\
\hline & 1 & 2 & 3 & 4 \\
\hline SITUATIONAL VARIABLES & \multirow[b]{3}{*}{ - } & \multirow[b]{3}{*}{ - } & \multirow[b]{2}{*}{ - } & \multirow{3}{*}{$\varnothing$} \\
\hline Purchase in a physical store & & & & \\
\hline High dissatisfaction & & & - & \\
\hline \multicolumn{5}{|l|}{ INDIVIDUAL VARIABLES } \\
\hline Redress seeking & - & - & - & - \\
\hline Individual's assertiveness & - & - & & - \\
\hline Social media habit strength & $\varnothing$ & & - & - \\
\hline \multicolumn{5}{|l|}{ CHANNEL-RELATED VARIABLES } \\
\hline Perceived channel convenience & & $\varnothing$ & - & - \\
\hline Perceived benefits of store employees & & & & e \\
\hline Raw coverage & 0.43 & 0.25 & 0.24 & 0.15 \\
\hline Unique coverage & 0.05 & 0.03 & 0.02 & 0.08 \\
\hline Consistency & 0.87 & 0.90 & 0.82 & 0.74 \\
\hline
\end{tabular}

Overall solution coverage: 0.75 .

Overall solution consistency: 0.84 .

${ }^{\mathrm{a}}$ indicates the presence of a condition. $\varnothing$ indicates its absence. Large circles indicate core conditions, and small ones represent peripheral conditions. Blank spaces indicate "don't care".

Note: This table excludes those solutions with very low unique coverage (lower than 0.00 ).

conditions" (Ragin, 2006:305), that is, the share of the outcome explained by a configuration. Unique coverage assesses the weight of the configuration, that is, the share of the outcome explained uniquely by the configuration (Schneider \& Wagemann, 2010).

According to data shown in Table 1, for complaining at the store, at least two different types of variables (situational, individual and/or channel-related) have to combine in presence or absence. All three types of variables play a core role in the solutions: situational variables (in solutions 1, 3 and 4), individual variables (in solutions 1 and 3) and channel-related variables (in solutions 2 and 4). Solution 1 is the only one where channel-related variables play no role; this solution suggests that highly dissatisfied individuals motivated by redress seeking, who are highly assertive (core condition) and have no strong social media habit (core condition) will complain at the store. Solutions 2, 3, and 4 show that the presence of the three types of variables leads to a complaint at the store. Solution 2 identifies those individuals that, being dissatisfied, motivated by redress seeking and being assertive, will complain at the physical store even if they do not perceive its convenience (core condition). Solution 3 is determined by the core role of offline purchase, high dissatisfaction and redress seeking, however, social media habit strength, and channel convenience also play a role. Finally, solution 4 groups online buyers who are aware of the benefits of store employees (both being core conditions); moreover, they consider the physical store a convenient channel for complaining, are looking for redress, are assertive, and have strong social media habit; it is also relevant to highlight that dissatisfaction does not play any specific role in this solution.

From these results, we can highlight that individual variables are essential; more precisely, redress seeking is a crucial aspect for complaining at the physical store as it appears in all four solutions, although it plays a core role just in one solution. Similar reasoning applies regarding the individual variable assertiveness and the situational variable high dissatisfaction, as they are present in three of the four solutions, high dissatisfaction playing a core role in two solutions. Finally, it is also worth highlighting that the channel of purchase does not really condition the channel of complaint as it appears with a core role in two of the four solutions (solutions 3 and 4), but in each case, the channel of purchase is different (offline in solution 3 and online in solution 4). 


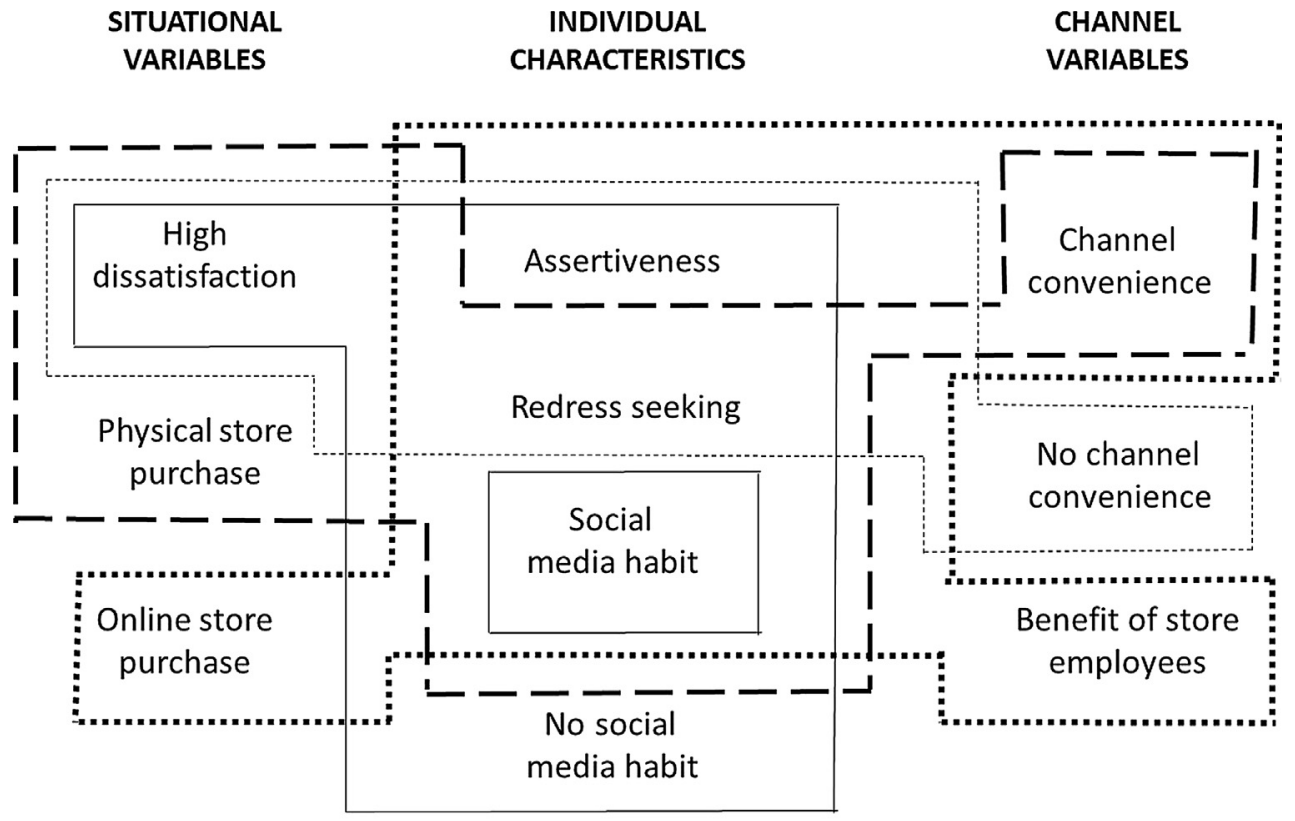

\section{Solution $1 \quad \cdots-. .-$ Solution $2 \quad-$ Solution 3}

Solution 4

Fig. 2. Graphic summary of sufficient conditions configurations.

Fig. 2 summarises the four solutions graphically, showing the relationships among the causal conditions.

These findings provide support to the general proposition: more than one causal configuration can lead to complain at the store, as fsQCA provided four solutions to the same outcome. Moreover, proposition 1 is partially supported; choosing the store to complain is related to (b) high dissatisfaction, (c) high redress seeking motivation, (d) high individual's assertiveness, and (f) high perception of store employees' benefits, but not explicitly related to (a) purchasing offline, (e) low social media habit strength, or (c) high perception of channel convenience, as these three variables are present or absent depending of the solution. Regarding Proposition 2, the results support only two of the four suggested combinations of causal conditions that can produce the outcome: choosing the store to complain relates to (a) offline purchase and motivation of redress seeking, and (b) low social media habit strength and high individual's assertiveness. Additionally, other causal configurations that we did not contemplate emerged, as buying online while being aware of the benefits of store employees in managing a complaint. The configurational approach used in this study permits to capture complexity, as it identifies sets of different configurations which consist of "patterns of attributes" (Fiss, 2007:1181) that can differ from the statistically significant main effects identified at a variable-level analysis. In fact, within those configurations, one causal condition may either be present or absent depending on how it combines with other causal conditions (proposition 2). We can observe that in solution 1, social media habit strength has to be present (has to be high) whereas in solution 3 , it has to be absent (has to be low).

We extended the analysis of the sufficient conditions by ascertaining whether some of the causal conditions were necessary for the individual to complain at the physical store. A causal condition is necessary for the outcome if it is needed for an outcome to occur (Ragin, 2000, 2008). The minimum values for necessity of a causal condition are 0.90 for consistency and 0.75 for coverage (Ragin, 2006). As Table 2 suggests, of the seven conditions considered, only high dissatisfaction and redress seeking are necessary conditions for complaining at the physical store. Individual's assertiveness reaches the minimum value for coverage but, although extremely close, it fails to reach the minimum value for consistency. Based on this result, we created a new variable as the
Table 2

Analysis of necessary conditions.

\begin{tabular}{lll}
\hline Causal conditions & Consistency & Coverage \\
\hline Purchase in a physical store & 0.59 & 0.84 \\
Purchase in an online store & 0.41 & 0.81 \\
High dissatisfaction & $\mathbf{0 . 9 2}$ & $\mathbf{0 . 8 3}$ \\
Redress seeking & $\mathbf{0 . 9 4}$ & $\mathbf{0 . 8 3}$ \\
Individual's assertiveness & 0.89 & 0.83 \\
Social media habit strength (absence) & 0.31 & 0.88 \\
Perceived channel convenience & 0.72 & 0.80 \\
Perceived benefits of store employees & 0.75 & 0.85 \\
High dissatisfaction * assertiveness * redress seeking & $\mathbf{0 . 9 8}$ & $\mathbf{0 . 8 3}$ \\
\hline
\end{tabular}

Bold means values that exceed the minimum consistency and coverage thresholds.

intersection of high dissatisfaction, redress seeking, and assertiveness as the three causal conditions were present in most of the sufficient configurations (Table 1). This new causal configuration reached the threshold values of consistency and coverage to be considered a necessary condition.

Based on the presence of the redress seeking variable in the results, we can say that it plays a central role in the analysis. Moreover, fsQCA suggests that experiencing a high level of dissatisfaction, and perceiving oneself as assertive are, on their own, necessary conditions for complaining at the physical store, and moreover, each of them is also present (combined with other variables) in three out of four solutions.

Achieving a good model fit does not necessarily mean that the model offers good predictions. Accordingly, in order to test the predictive validity of the results and following the same procedure of previous studies with the same methodology (e.g., Pappas et al., 2016), the sample was randomly split into a modelling subsample and a holdout subsample; the analysis was then repeated for each subsample. When testing predictive validity, only the overall solution consistency and coverage values for the subsample are expected to be similar to those for the whole sample; configurations for the subsample are not expected to be the same. Table 3 shows that the overall solution consistency and coverage values in the modelling subsample are similar to those for the whole sample (provided in Table 1). 
Table 3

Complex configurations leading to a complaint at the physical store for the modelling subsample.

\begin{tabular}{|c|c|c|c|}
\hline Models for subsample 1 & Raw coverage & Unique coverage & Consistency \\
\hline Model 1: STOREP*REDRE*ASSERT*CONV*EMPL & 0.33 & 0.15 & 0.85 \\
\hline Model 2: $\sim$ STOREP*DISSAT*REDRE* $\sim$ SM $^{*}$ CON*EMPL & 0.16 & 0.10 & 0.90 \\
\hline Model 3: DISSAT*REDRE*ASSERT* ${ }^{*}$ CONV & 0.23 & 0.06 & 0.86 \\
\hline Model 4: DISSAT*REDRE*ASSERT* $\sim$ EMPL & 0.23 & 0.04 & 0.77 \\
\hline
\end{tabular}

Solution coverage: 0.70 .

Solution consistency: 0.86 .

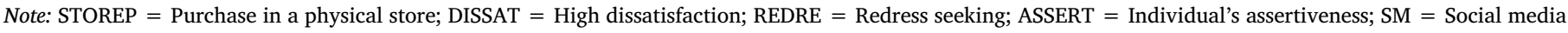
habit strength; CONV = Perceived channel convenience; EMPL = Perceived benefit of store employees.

* = and; $\sim=$ absence (negative).

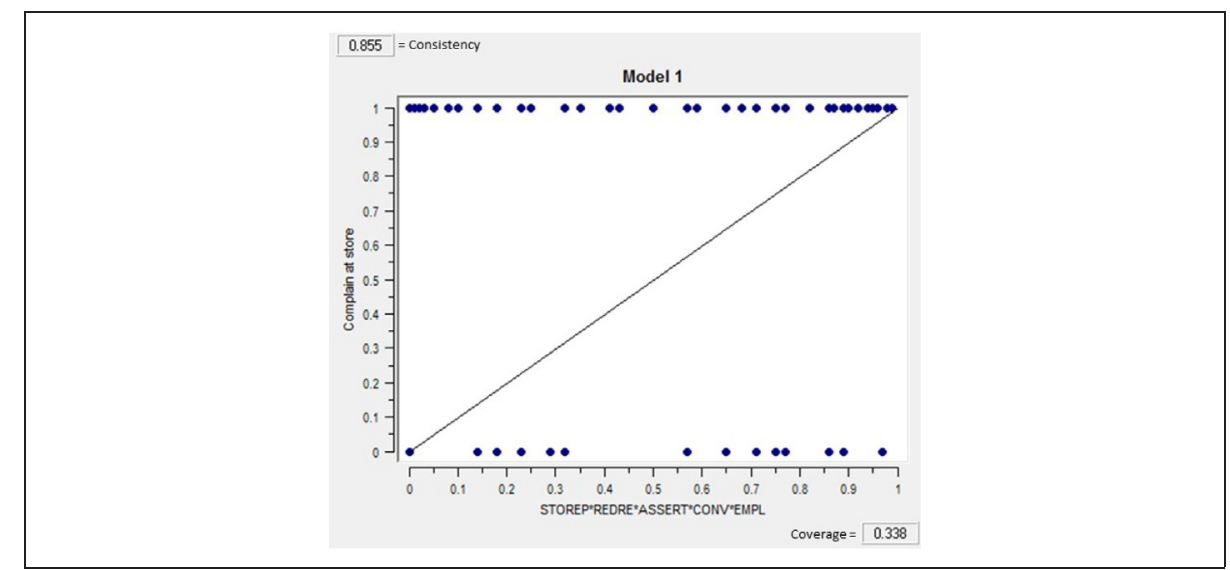

Fig. 3. Test of model 1 from the subsample using data from the holdout subsample. Note: Each dot in the XY plot represents one or more cases (i.e., individuals) in the study-some individuals have the same scores in the plot. STOREP = Purchase in a physical store; REDRE = Redress seeking; ASSERT = Individual's assertiveness; CONV $=$ Perceived channel convenience; EMPL $=$ Perceived benefit of store employees.

Note: Each dot in the XY plot represents one or more cases (i.e., individuals) in the study - some individuals have the same scores in the plot.

STOREP $=$ Purchase in a physical store; REDRE = Redress seeking; ASSERT = Individual's assertiveness; $\mathrm{CONV}=$ Perceived channel convenience; $\mathrm{EMPL}=$

Perceived benefit of store employees

We tested the results presented in Table 3 against the second subsample (the holdout subsample). Fig. 3 shows the results for model 1 of Table 3 (STOREP*REDRE*ASSERT*CONV*EMPL), but we tested all the models. As model 1 involved the combination of five causal conditions, it was necessary to model the configuration as a single variable. Y-axis represents the outcome, and $\mathrm{X}$-axis represents the causal conditions of model 1 from the subsample. Values in both axes can range from 0 (fully out: absence) to 1 (fully in: presence). Thus, Fig. 3 shows graphically how each case or individual (in the form of a dot) scores in the outcome variable and the configuration of model 1 . We can see that individuals score 0 or 1 in the outcome (Y-axis) because it was a dichotomous scale, taking the value 0 if the individual did not choose the physical store to complain and 1 if he/she did. However, for the X-axis other values between 0 and 1 are possible, as before calibration, the original variables ranged from 1 to 7 . Based on those scores, we calculated coverage (proportion of memberships in the outcome that is explained by the solution) and consistency (degree to which membership in the solution is a subset of membership in the outcome). For model 1 from the modelling subsample, the raw coverage $(0.33)$ and consistency (0.85) values (see data from Table 3 ) are the same as those values obtained when testing the same model using data from the holdout subsample (coverage $=0.33$ and consistency $=0.85$, see Fig. 3). Although these values are equal in both subsamples, for predictive validity, it is enough that they are similar. According to the results of the tests for the four models linked to the outcome, the results have high predictive validity.

\section{Discussion and implications}

\subsection{Theoretical implications}

Our study contributes, on the one hand, to the literature on channels by showing the interactions between channels across the shopping process, and on the other hand to the literature on CCB by uncovering the role of variables specific to the omnichannel retail context in complaint channel choice.

By following the logic of the S-O-R framework, we suggest that omnichannel retail shoppers choose to complain at the store - despite having other online channels available - as a result of the joint influence of external stimuli (situational and channel-related variables) and personal characteristics.

The purchase channel was one of the two situational variables in our research design, arguing for the existence of channel dependencies between subsequent shopping stages (Gensler et al., 2012). Previous findings on postpurchase complaining (Lee \& Cude, 2012; Frasquet et al., 2017) using regression-based methodologies have found a lock-in effect of channels for offline buyers. In contrast, our results show that this effect is not the main one, as purchase at the store plays a role in only one of the four solutions. Moreover, purchasing online is a core variable in one of the solutions, which points out the existence of crossshopping behaviours.

The second situational variable in our research framework, dissatisfaction, is a critical variable in CCB research. Our results confirm the significant role of dissatisfaction in complaining as three of the four solutions require high dissatisfaction. The literature that provides evidence on the role of dissatisfaction in the choice of complaint channel 
(as opposed to complaint intention) is very scarce. In this line, our results confirm the suggestion of Mattila and Wirtz (2004) in that high dissatisfaction is related to the choice of interactive complaint channels. Our findings are somewhat different to Lee and Cude (2012), who found high dissatisfaction to affect online buyers; on the one hand our results show that high dissatisfaction is a necessary condition for shoppers to choose the store to complain, but on the other hand, high dissatisfaction does not affect the choice of online buyers as it does for offline buyers

An interesting finding of the fsQCA analysis results is that high dissatisfaction always needs to be combined with high redress seeking motivation to encourage individuals to visit the store to voice the complaint face-to-face. This result supports the findings of Mattila and Wirtz (2004) in that those individuals seeking redress or compensation from the firm would prefer interactive channels. When dissatisfaction does not appear in the solution (solution 4), i.e. it does not play a specific important role, the three individual-related variables have to be present; this demonstrates that personality traits play a role in explaining the diversity of consumer reactions to a dissatisfactory event (Lau \& Ng, 2009). The core role of the functions performed by salespersons at the store (solution 4) adds to the literature on the relevance of store employees in terms of affecting the behaviour of consumers during the shopping process (O'Cass \& Grace, 2008). The channel-related variable of convenience appears in two of the solutions (although not with a core role), and it is absent (with a core role) in one solution. This finding is an interesting contribution to the literature on channel choice which argues that consumers would choose the channel perceived as more convenient (Gensler et al., 2012). A possible explanation is that, even though shoppers may perceive online channels to be more convenient (Schöreder \& Zaharia, 2008), when they find it necessary to solve a dissatisfactory incident they would take the time and effort to go the store in the hope that this option will prove more effective.

By applying complexity theory and fsQCA, the results of this study imply that omnichannel complaint behaviour, and more specifically the choice of the store to complain, is a complex phenomenon that does not have a single answer. Based on individual-level data, this methodology is a complementary approach to other research methodologies (e.g., SEM) showing how external stimuli (situational and channel-related variables) and personal characteristics combine in complex ways to shape responses regarding the selection of the store as a complaint channel. The roles of external stimuli and personal characteristics do not ubiquitously apply to all customers complaining at the store. It is possible to identify specific variables which are common to cases in which the individual decides to complain at the store (necessary conditions), but they are not sufficient to explain such behaviour. Rather than one single element, different combinations of situational variables, channel-related variables, and personal characteristics result in voicing the complaint at the store. As Crilly (2011) highlights, fsQCA bridges conventional qualitative and quantitative analyses by combining the complexity of case analysis with a degree of generalisability through formal analysis.

\subsection{Managerial implications}

Our results suggest directions to improve customer complaint management for multi- or omnichannel retailers. This study highlights a new role for the physical store in the postpurchase stage with regards to managing customer complaints. In this sense, an interesting finding of our study is that, irrespective of the purchase channel, most shoppers will go to the physical store to complain if they are highly dissatisfied, seek redress and are assertive.

Moreover, customers are likely to visit the store even when they do not consider it a convenient channel to voice a complaint. Interestingly, our results suggest that there is a group of online buyers who do not have to be highly dissatisfied in order to choose to complain at the store. Thus, retailers should pay increased attention to postpurchase customer service at the store to serve both offline and online buyers seeking a remedy or compensation from the firm when a failure occurs. In the current omnichannel retail era, large numbers of physical stores are closing every year and the ones staying are redefining their role to provide increased customer value (Bell et al., 2018). We argue that physical stores can provide increased value to omnichannel customers not only by enhancing the purchase experience but also the postpurchase experience.

The results regarding the individual variable of social media habit strength indicate that both online and offline buyers are driven to stores when they are not particularly familiar with social media (solution 1) or when, being familiar, they think the offline channel is convenient (solution 3), and they believe store employees can provide added value (solution 4). The popularity of social media and the risk of negative opinions spreading to a broad audience challenges firms (Balaji, Jha, \& Royne, 2015); multichannel retailers have the advantage of being able to deal with complaints privately at the store. Retailers will benefit from the advantages of this channel if they communicate on their websites that customers are welcome at the store to solve issues with online purchases. Again, well-trained employees providing excellent customer service at the store will benefit the face-to-face voicing of the complaint.

Many customers fail to voice their complaints simply because of the burden involved in doing so. Implementing easy to use and efficient mechanisms to help customers communicate their dissatisfaction would contribute to an increased rate of customers that voice their complaints. Face-to-face interaction offers increased opportunities to solve the issue and try to recover dissatisfied customers (Mattila \& Wirtz, 2004). In the current omnichannel retail context, physical stores should complement online channels and provide increased utility to shoppers (Bell et al., 2018). An evident aspect where offline channels can stand out from online channels is the person-to-person relationship. Retailers would benefit from training employees to provide increased benefits for customers as this would encourage them to complain in-store; consequently, they would also benefit from a higher likelihood of successful service recovery. Thus, the new role of the physical store is a building block in the provision of motivated and qualified staff who can provide real value for any customer regardless of the channel through which he or she has purchased.

\subsection{Limitations and future research}

This study has several limitations originating from its research design. First of all, the study was undertaken only in Spain. Although the vast majority of the population in this country uses the internet $-80 \%$ in 2017, according to Eurostat, (2018) - the generalisation of our results is limited as a consequence. Furthermore, the omnichannel behaviour required for participating in the survey referred to a single product category (apparel). Future research should examine and compare additional product categories. Another limitation of the study is the technique of scenario manipulation employed; although this is a standard method in the CCB literature, other methods that analyse a real issue, such as the critical incident technique, could be used. Future research could also consider different scenarios resulting in different levels of dissatisfaction.

Moreover, our study focused on complaints voiced to the firm, leaving out complaints to third parties (e.g., peers, consumer rights organisations). As future research, we suggest to investigate the underlying reasons for complaining to third parties. Further studies could also extend the amount of evidence by analysing the choice of other complaint channels such as email or social media. Furthermore, we included channel convenience as a condition leading to complaint channel choice; future research could also consider perceived channel effectiveness. 


\section{Conclusions}

This study has employed complexity theory and fsQCA to understand the choice of the store as a postpurchase complaint channel in the omnichannel context. Our findings show that several types of variables - situational, individual, and channel-related - combine to explain when shoppers complain at the store. Thus, we conclude that the choice of the physical store to complain in the omnichannel era does not have a single answer; more specifically four solutions are found, in which at least two types of variables have to combine.

An interesting conclusion of our study is regarding the role of high dissatisfaction. There is abundant research investigating the effect of dissatisfaction on the intention to complain but not on complaint channel choice. Our results show that high dissatisfaction is, in fact, a necessary condition for complaining at the store, but other variables have to add to it to take customers to the store to complain. The redress seeking motivation is the second necessary condition for store complaining. As well, the interaction of the three variables of high dissatisfaction, redress seeking, and assertiveness works as a necessary condition for complaining at the store. The results also highlight that the perception of the benefits of store employees is a core condition in one of the solutions. Finally, an interesting conclusion of our study for multi- and omnichannel research is that the purchase channel does not affect the choice of complaint channel, that is, both online and offline buyers would choose the store when they seek redress and other conditions (i.e., high assertiveness, perceived benefits of employees) apply.

These conclusions offer meaningful implications to multi- and omnichannel retailers. Retailers should provide integrated complaint management at the physical store to serve different profiles of dissatisfied customers, who include both offline and online buyers. Companies should empower store employees to try to recover the goodwill of dissatisfied customers. Retailers should strive to solve issues face-to-face to prevent dissatisfied customers from voicing negative opinions on social media, which is becoming a common practice in the current omnichannel context.

\section{Acknowledgements}

This paper was financed by the Spanish Ministry of Science, Innovation and Universities, Spanish State Research Agency (Research Grant ECO 2017-83051-R).

\section{Appendix A. Supplementary material}

Supplementary data to this article can be found online at https:// doi.org/10.1016/j.jbusres.2019.09.057.

\section{References}

Ailawadi, K. L., \& Farris, P. W. (2017). Managing multi- and omni-channel distribution: Metrics and research directions. Journal of Retailing, 93(1), 120-135.

Balaji, M. S., Jha, S., \& Royne, M. B. (2015). Customer e-complaining behaviours using social media. Service Industries Journal, 35(11-12), 633-654.

Bearden, W. O., \& Teel, J. E. (1983). Selected determinants of consumer satisfaction and complaint reports. Journal of Marketing Research, 20(1), 21.

Bell, D. R., Gallino, S., \& Moreno, A. (2018). The store is dead-long live the store. MIT Sloan Management Review, 59(3), 1-10.

Berry, R., Tanford, S., Montgomery, R., \& Green, A. J. (2018). How we complain: The effect of personality on consumer complaint channels. Journal of Hospitality and Tourism Research, 42(1), 74-101.

Cervellon, M. C., Sylvie, J., \& Ngobo, P. V. (2015). Shopping orientations as antecedents to channel choice in the French grocery multichannel landscape. Journal of Retailing and Consumer Services, 27, 31-51.

Clark, J. (2013). Conceptualising social media as complaint channel. Journal of Promotional Communications, 1(1), 104-124.

Crilly, D. (2011). Predicting stakeholder orientation in the multinational enterprise: A mid-range theory. Journal of International Business Studies, 42(5), 694-717.

Dalla Pozza, I., Heitz-Spahn, S., \& Texier, L. (2017). Generation Y multichannel behaviour for complex services: The need for human contact embodied through a distance relationship. Journal of Strategic Marketing, 25(3), 226-239.

Day, R. L. (1984). Modeling choices among alternative responses to dissatisfaction.
Advances in Consumer Research, 11, 496-499.

Day, R. L., \& Landon, E. L. (1977). Toward a theory of consumer complaining behavior. Consumer and Industrial Buying Behavior, 95(1), 425-437.

De Keyser, A., Schepers, J., \& Konuş, U. (2015). Multichannel customer segmentation: Does the after-sales channel matter? A replication and extension. International Journal of Research in Marketing, 32(4), 453-456.

Eurostat (2018). "Internet access and use statistics - households and individuals" Accessed on 16/07/2018 at < http://ec.europa.eu/eurostat/web/digital-economy-andsociety/data/main-tables $>$.

Fiss, P. C. (2007). A set-theoretic approach to organizational configurations. Academy of Management Review, 32(4), 1180-1198.

Frambach, R. T., Roest, H. C. A., \& Krishnan, T. V. (2007). The impact of consumer internet experience on channel preference and usage intentions across the different stages of the buying process. Journal of Interactive Marketing, 21(2), 26-41.

Frasquet, M., Miquel, M. J., \& Mollá, A. (2017). Complaining at the store or through social media: The influence of the purchase channel, satisfaction, and commitment. Advances in National Brand and Private Label Marketing, 87-94.

Frasquet, M., Mollá, A., \& Ruiz, E. (2015). Identifying patterns in channel usage across the search, purchase and post-sales stages of shopping. Electronic Commerce Research and Applications, 14(6), 654-665.

Gensler, S., Verhoef, P. C., \& Böhm, M. (2012). Understanding consumers' multichannel choices across the different stages of the buying process. Marketing Letters, 23(4), 987-1003.

Hirschman, A. O. (1970). Exit, voice, and loyalty. Cambridge, MA: Harvard University Press.

Istanbulluoglu, D., Leek, S., \& Szmigin, I. T. (2017). Beyond exit and voice: Developing an integrated taxonomy of consumer complaining behaviour. European Journal of Marketing, 51(5/6), 1109-1128.

Juaneda-Ayensa, E., Mosquera, A., \& Murillo, Y. S. (2016). Omnichannel customer behavior: Key drivers of technology acceptance and use and their effects on purchase intention. Frontiers in Psychology, 7(Jul), 1-11.

Konuş, U., Verhoef, P., \& Neslin, S. (2008). Multichannel shopper segments and their covariates 败. Journal of Retailing, 84(4), 398-413.

Lapinski, M. K., \& Orbe, M. P. (2007). Evidence for the construct validity and reliability of the co-cultural theory scales. Communication Methods and Measures, 1(2), 137-164.

Larose, R., \& Eastin, M. S. (2004). A social cognitive theory of internet uses and gratifications: toward a new model of media attendance. Journal of Broadcasting \& Electronic Media, 48(3), 358-377.

Larose, R., Lin, C. A., Eastin, M. S., Larose, R., Lin, C. A., Unregulated, M. S. E., ... Eastin, M. S. (2003). Unregulated internet usage: Addiction, habit, or deficient self-regulation? Unregulated internet usage: Addiction, habit, or deficient self-regulation? Media Psychology, 5(3), 225-253.

Lau, G. T., \& Ng, S. (2009). Individual and situational factors influencing negative wordof-mouth behaviour. Canadian Journal of Administrative Sciences / Revue Canadienne Des Sciences de l'Administration.

Lee, S., \& Cude, B. J. (2012). Consumer complaint channel choice in online and offline purchases. International Journal of Consumer Studies, 36(1), 90-96.

Leischnig, A., \& Kasper-Brauer, K. (2015). Employee adaptive behavior in service enactments. Journal of Business Research, 68(2), 273-280.

Lemon, K. N., \& Verhoef, P. C. (2016). Understanding customer experience throughout the customer journey. Journal of Marketing, 80(6), 69-96.

Mattila, A. S., \& Wirtz, J. (2004). Consumer complaining to firms: The determinants of channel choice. Journal of Services Marketing, 18(2), 147-155.

Mattila, A. S., \& Wirtz, J. (2008). The role of store environmental stimulation and social factors on impulse purchasing. Journal of Services Marketing 22(7), 562-567.

Mehrabian, A., \& Russell, J. A. (1974). An Approach to Environmental Psychology. Cambridge, Mass: MIT Press.

Mozas-Moral, A., Bernal-Jurado, E., Medina-Viruel, M. J., \& Fernández-Uclés, D. (2016). Factors for success in online social networks: An fsQCA approach. Journal of Business Research, 69(11), 5261-5264.

O'Cass, A., \& Grace, D. (2008). Understanding the role of retail store service in light of self-image-store image congruence. Psychology and Marketing, 25(6), 521-537.

Pappas, I. O., Kourouthanassis, P. E., Giannakos, M. N., \& Chrissikopoulos, V. (2016). Explaining online shopping behavior with fsQCA: The role of cognitive and affective perceptions. Journal of Business Research, 69(2), 794-803.

Ragin, C. C. (2000). Fuzzy-set Social Science. Chicago, IL: The University of Chicago Press.

Ragin, C. C. (2006). Set relations in social research: Evaluating their consistency and coverage. Political Analysis, 14(3), 291-310.

Ragin, C. C. (2008). Redesigning Social Inquiry: Fuzzy Sets and Beyond. Chicago, IL: The University of Chicago Press.

Reynolds, K. E., \& Arnold, M. J. (2000). Customer loyalty to the salesperson and the store: Examining relationship customers in an upscale retail context. Journal of Personal Selling \& Sales Management, 20(2), 89-98.

Reynolds, K. E., \& Beatty, S. E. (1999a). A relationship customer typology. Journal of Retailing, 75(4), 509-523.

Reynolds, K. E., \& Beatty, S. E. (1999b). Customer benefits and company consequences of customer-salesperson relationships in retailing. Journal of Retailing, 75(1), 11-32.

Sands, S., Ferraro, C., Campbell, C., \& Pallant, J. (2016). Segmenting multichannel consumers across search, purchase and after-sales. Journal of Retailing and Consumer Services, 33, 62-71.

Schneider, C., \& Wagemann, C. (2010). Standards of good practice in qualitative comparative analysis (QCA) and fuzzy-sets. Comparative Sociology, 9(3), 397-418.

Schröder, H., \& Zaharia, S. (2008). Linking multi-channel customer behavior with shopping motives: An empirical investigation of a German retailer. Journal of Retailing and Consumer Services, 15(6), 452-468.

Singh, J. (1988). Consumer complaint intentions and behavior: Definitional and 
taxonomical issues. Journal of Marketing, 52(1), 93.

Snellman, K., \& Vihtkari, T. (2003). Customer complaining behaviour in technologybased service encounters. International Journal of Service Industry Management, 14(2), 217-231.

Svari, S., \& Erling Olsen, L. (2012). The role of emotions in customer complaint behaviors. International Journal of Quality and Service Sciences, 4(3), 270-282.

Thøgersen, J., Juhl, H. J., \& Poulsen, C. S. (2009). Complaining: A function of attitude, personality, and situation. Psychology \& Marketing, 26(8), 760-777.

Tronvoll, B. (2011). Negative emotions and their effect on customer complaint behaviour. Journal of Service Management, 22(1), 111-134.

van Bruggen, G. H., Antia, K. D., Jap, S. D., Reinartz, W. J., \& Pallas, F. (2010). Managing marketing channel multiplicity. Journal of Service Research, 13(3), 331-340.

Verhoef, P. C., Kannan, P. K., \& Inman, J. J. (2015). From Multi-Channel Retailing to Omni-Channel Retailing Introduction to the Special Issue on Multi-Channel Retailing ¿. Journal of Retailing, 91(2), 174-181.

Verhoef, P. C., Neslin, S. a., \& Vroomen, B. (2007). Multichannel customer management: Understanding the research-shopper phenomenon. International Journal of Research in Marketing, 24(2), 129-148.

Woodside, A. G. (2013). Moving beyond multiple regression analysis to algorithms: Calling for adoption of a paradigm shift from symmetric to asymmetric thinking in data analysis and crafting theory. Journal of Business Research, 66(4), 463-472.

Woodside, A. G. (2016). The good practices manifesto: Overcoming bad practices pervasive in current research in business. Journal of Business Research, 69(2), 365-381.

Wu, I. L. (2013). The antecedents of customer satisfaction and its link to complaint intentions in online shopping: An integration of justice, technology, and trust. International Journal of Information Management, 33(1), 166-176.

Zhang, M., Ren, C., Wang, G. A., \& He, Z. (2018). The impact of channel integration on consumer responses in omni-channel retailing: The mediating effect of consumer empowerment. Electronic Commerce Research and Applications, 28, 181-193.

\section{Further reading}

Moliner, B., Berenguer, G., Gil, I., \& Fuentes, M. (2006). Antecedents to complaint behaviour in the context of restaurant goers. The International Review of Retail, Distribution and Consumer Research, 16(5), 493-517.

Maria-Jose Miquel-Romero is an Associate Professor of the Marketing Department at the University of Valencia, Spain. She has been Academic Director of the Master in Marketing and Market Research at the School of Business at the University of Valencia, and also coordinator of the Master in Marketing and Communication at the same University. Her research interests include advertising, private labels, omnichannel retailing, and consumer behavior. She has co-authored different book chapters and academic publications in indexed journals on the topics of her interest. She was a visiting scholar at the University of Glasgow, Scotland (UK), at University of Salford - Manchester (UK), and at HEC Montréal - Montreal (Canada).

Marta Frasquet is an Associate Professor of the Marketing Department at the University of Valencia, Spain. She has been Academic Director of the International Master of Business Administration (iMBA) at the University of Valencia. Her main teaching and research interests are in the field of distribution channels, retailing, logistics and consumer behaviour. She has a significant number of contributions to international conferences and papers published in international journals. She has been invited professor at the University of Edinburgh (UK), at the Universitá Bocconi, Milan (Italy), at Regent's College, London (UK), at Dublin Institute of Technology (Ireland), and at the University of North Carolina (EE.UU.)

Alejandro Molla-Descals, is a Professor of the Marketing Department at the University of Valencia, Spain. He has been Academic Director of the Master of Business Administration (MBA) at the University of Valencia. His research interests include international marketing, strategic marketing, distribution channels and retailing. He has a significant number of contributions to international conferences and papers published in international indexed journals. 